VOL. 3, NO. 1, Juni 2019

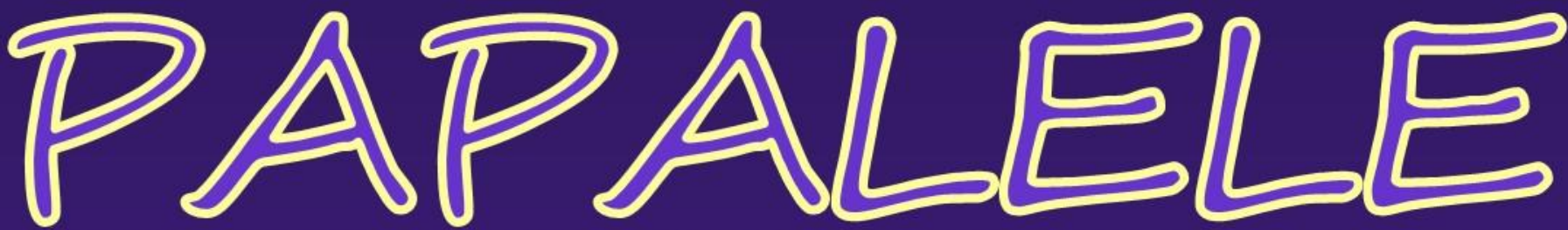
JURNAL PENELITIAN SOSIAL EKONOMI PERIKANAN DAN KELAUTAN

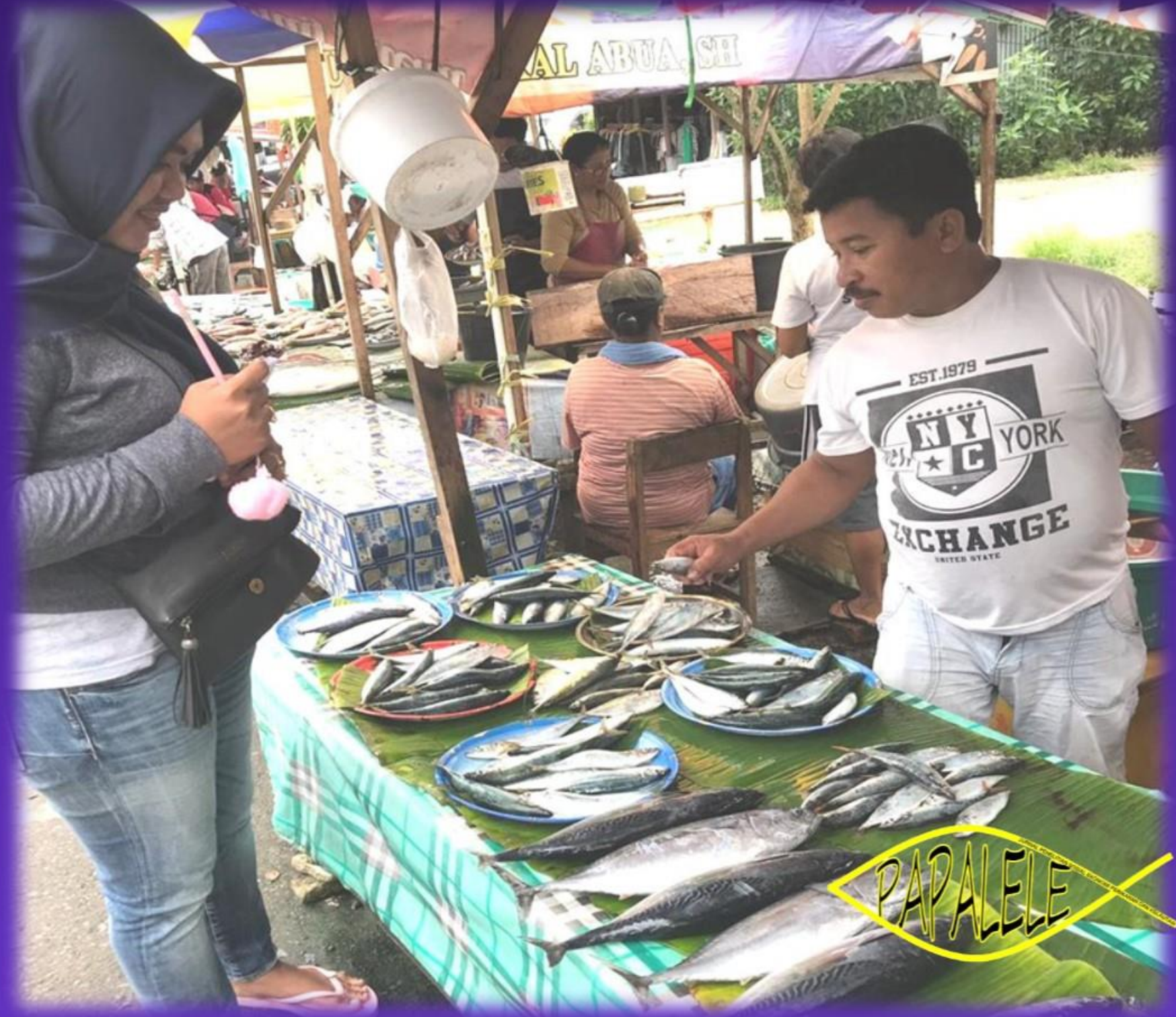

PAPALELE-JURNAL PENELITIAN SOSIAL EKONOMI PERIKANAN DAN KELAUTAN
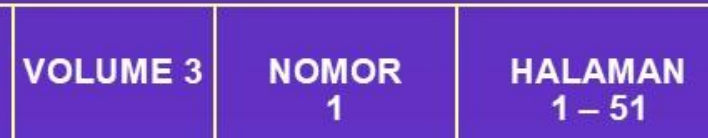

JUNI 2019

ISSN 2580-0787

Diterbitkan oleh:

F 2 PROGRAM STUDI AGRIBISNIS PERIKANAN

mas FAKULTAS PERIKANAN DAN ILMU KELAUTAN 


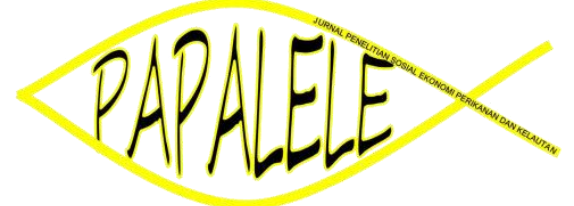

\section{JURNAL \\ PENELITIAN SOSIAL EKONOMI PERIKANAN DAN KELAUTAN}

\author{
PENANGGUNG JAWAB \\ Ketua Program Studi Sosial Ekonomi Perikanan \\ KETUA DEWAN REDAKSI \\ D. Bawole
}

RADAKTUR AHLI

V. Nikijuluw, M.S. Baskoro, J. Hiariej, F. Rieuwpassa, P. Wenno

REDAKTUR PELAKSANA

St. M. Siahainenia, R.L. Papilaya, Y. Lopulalan, Y.M.T.N. Apituley, V.J. Pical, W. Talakua, E. Talakua

PELAKSANA TATA USAHA

L.M. Soukotta, A. Ruban, K. Pattimukay, J. Sangaji, F. de Lima

PENERBIT

Program Studi Sosial Ekonomi Perikanan Jurusan Agrobisnis Perikanan

Fakultas Perikanan dan Ilmu Kelautan Universitas Pattimura

\section{ALAMAT REDAKTUR}

Program Studi Sosial Ekonomi Perikanan Jurusan Agrobisnis Perikanan Fakultas Perikanan dan Ilmu Kelautan Universitas Pattimura

Jln. Mr. Chr. Soplanit Poka-Ambon Telp. (0911) 379859. Fax 379196

PAPALELE merupakan jurnal penelitian ilmu sosial ekonomi perikanan dan kelautan yang menyajikan artikel tentang hasil penelitian yang berkaitan dengan bidang sosial ekonomi perikanan dan kelautan. Setiap naskah yang dikirim akan dinilai secara kritis oleh tim penilai yang relevan sebelum diterbitkan. Jurnal ini diterbitkan dua kali setahun, bulan Juni dan Desember. 


\section{KATA PENGANTAR}

Puji dan syukur kami panjatkan kepada Tuhan Yang Maha Esa atas rahmat-Nya. Jurnal PAPALELE, Jurnal penelitian Sosial Ekonomi Perikanan dan Kelautan kembali diterbitkan.

PAPALELE, Jurnal penelitian Sosial Ekonomi Perikanan dan Kelautan sesuai dengan Keputusan Lembaga Ilmu Pengetahuan Indonesia Nomor 0005.25800787/JI.3.1.SK.ISSN/2017.0529 Mei 2017 telah mengeluarkan nomor ISSN 2580-0787 untuk mulai penerbitan edisi volume 1 nomor 1, Juni 2017, dan sekarang melanjutkan perebitan untuk edisi volume 3 nomor 1, Juni 2019. Pada edisi ini, sama seperti edisi sebelumnya ditampilkan lima tulisan penelitian yang berkaitan dengan ilmu sosial ekonomi perikanan dan kelautan.

Dengan diterbitkannya jurnal ini, diharapkan dapat memberikan informasi ilmiah di bidang sosial ekonomi perikanan dan kelautan kepada pembaca. Saran dan masukan dari pembaca sangat diharapkan guna kesempurnaan penerbitan jurnal di waktu depan.

$\underline{\text { REDAKSI }}$ 


\section{DAFTAR ISI}

Halaman

KATA PENGANTAR

DAFTAR ISI ii

EFISIENSI TEKNIS DAN EKONOMI PERIKANAN TUNA HAND LINE DI NEGERI TIAL KABUPATEN MALUKU TENGAH

Oleh: Priscyllia Franetha Siahainenia, Dionisius Bawole, dan Willem Talakua $1-10$

ANALISIS KELAYAKAN USAHA KERAMBA JARING APUNG (KJA) DENGAN SISTEM MONOKULTUR DAN POLIKULTUR DI TANJUNG MARTHAFONS KOTA AMBON

Oleh: Tiffany Evangeline Leatemia

KELAYAKAN USAHA POLE AND LINE DI NEGERI HATIVE KECIL KOTA AMBON

Oleh: Ferdinan W. M. Haulussy

PRODUKTIVITAS DAN RESIKO USAHA PERIKANAN PURSE SEINE

DI NEGERI LATUHALAT

Oleh: Robert Frento Pattipeilohy dan Eygner Gerald Talakua

EFISIENSI DAN KEBERLANJUTAN USAHA PURSE SEINE DI KABUPATEN MALUKU TENGAH DAN KOTA AMBON

Oleh: Margie Wattimury 


\title{
PRODUKTIVITAS DAN RESIKO USAHA PURSE SEINE DI NEGERI LATUHALAT
}

\section{PURSE SEINE BUSINESS PRODUCTIVITY AND RISK IN LATUHALAT VILLAGE}

\section{Robert Frento Pattipeilohy dan Eygner Gerald Talakua}

\author{
Program Studi Agrobisnis Perikanan, \\ Fakultas Perikanan dan Ilmu Kelautan, Universitas Pattimura \\ Penulis korespondensi: eygnertalakua@gmail.com \\ Diterima 4 September 2019, disetujui 7 Oktober 2019
}

\begin{abstract}
ABSTRAK
Penurunan produksi sumber daya pelagis kecil yang terjadi pada musim tersentu di perairan laut Kota Ambon berdampak pada kelangsungan usaha purse seine di Negeri Latuhalat dikarenakan penuruan produktvitas. Hal ini memunculkan tingginya risiko dalam berusaha, mengingat usaha perikanan tangkap memiliki karakteristik yang berbeda. Penelitian ini bertujuan untuk menghitung produktivitas dan risiko usaha purse seine di Desa Latuhalat. Metode penelitian yang digunakan adalah survei, pengambilan data primer dilakukan terhadap 5 pemilik usaha purse seine di Negeri Latuhalat sebagai responden dan dilakukan perhitungan produktivitas berdasarkan perbandingan nilai produksi dan total biaya serta perhitungan resiko usaha berdasarkan kerapatan probabilitas. Hasil penelitian menunjukkan bahwa, usaha purse seine di Negeri Latuhalat adalah produktif dengan nilai 1,28 untuk responden 1, responden 2, responden 3 dan responden 5 sedangkan dengan nilai 1,30 untuk responden 4 pada bulan Maret hingga Mei. Resiko usaha purse seine di Negeri Latuhalat dari bulan Maret hingga Mei (musim barat) adalah tinggi karena berpeluang mengalami kerugian sebesar Rp 10.140.219.45/bulan, Rp 5.906.561.73/bulan, Rp 5.280.774.25/bulan, Rp 4.463.428.57/bulan dan Rp 5.173.572.36/bulan.
\end{abstract}

Kata kunci: purse seine, produktivitas, resiko, Negeri Latuhalat.

\begin{abstract}
The decline of small pelagic resources production in Ambon sea waters during a certain season has an impact on the continuity of the purse seine business in Latuhalat Village. This poses a high business risk, given that capture fisheries have different characteristics. This study aims to calculate the productivity and risk of purse seine business in Latuhalat. Survey was conducted to collect primary data to 5 purse seine business owners in Latuhalat as respondents, and productivity calculations were carried out based on comparison of production values and total costs, as well as business risk calculations based on probability density. The results showed that the purse seine business in Latuhalat was productive with a value of 1.28 for respondents 1, 2, 3 and 5; and 1.30 for respondents 4 during March to May. The risk of purse seine business in Latuhalat from March to May (west season) is high because each respondent has the potential to experience losses of Rp10,140,219.45/month, Rp5,906,561.73/month, Rp5,280,774.25/month, Rp4. 463,428.57/month and Rp. 5,173,572,36/month.
\end{abstract}

Keywords: purse seine, productivity, risk, Latuhalat 


\section{PENDAHULUAN}

Perikanan tangkap di provinsi Maluku pada beberapa tahun terakhir ini mengalami peningkatan, sejalan dengan perkembangan alat tangkap. Beberapa alat tangkap yang teridentifikasi melakukan operasi penangkapan di wilayah pesisir dan perairan Laut Maluku, antara lain : jaring lingkar (purse seine), huhate (pole and line), pukat pantai (beach net), rumpon, pancing dasar, pancing tonda, jaring insang dasar, jaring insang hanyut, serta rawai. Pada tahun 2010 hingga 2014 terjadi peningkatan alat tangkap Purse seine di Maluku sebesar $20 \%$. Kontribusi alat tangkap ini terhadap total produksi ikan di Maluku pada tahun 2014 sebesar 35 ton atau $17 \%$ dari total produksi, sedangkan penggunaan alat tangkap ini sebesar $15 \%$ dari keseluruhan alat tangkap yang beroperasi di Maluku (Dinas Kelautan dan Perikanan Maluku, 2015).

Penurunan produksi sumber daya ikan pelagis kecil terkait dengan pemanfaatan yang melebihi potensi yang ada. Laporan Balai Penelitian Laut Jakarta (2014) menunjukkan bahwa, sumber daya ikan pelagis kecil di wilayah pengelolaan perikanan (WPP) 714 Teluk Tolo dan Laut Banda (terdapat perairan laut Kota Ambon) telah overfishing dan diusulkan untuk dilakukan moratorium upaya penangkapan.

Fenomena ini menggambarkan tingginya aktivitas masyarakat nelayan dalam memanfaatkan sumber daya ikan pelagis kecil untuk memenuhi kebutuhan ekonomi. Salah satu daerah penangkapan ikan pelagis kecil khususnya di wilayah Kota Ambon adalah Perairan Teluk Luar (TAL) dengan luas 98,78 $\mathrm{km}^{2}$. Perairan ini memiliki 5 jenis ikan yang mendominasi hasil tangkapan nelayan yaitu ikan layang (Decapterus spp), ikan selar (Selar crumenopthalmus), ikan tongkol (Auxis thazard, Euthynnus affinis) dan kembung (Rastralinger spp). Ikan-ikan ini umumnya tertangkap dengan alat tangkap pukat cincin (purse seine). Purse seine saat ini di Kota Ambon berjumlah 78 unit tersebar di 5 kecamatan yaitu Kecamatan Sirimau 10 unit, Leitimur Selatan 10 unit, Teluk Ambon 23 unit, Teluk Ambon Baguala 7 unit dan Nusaniwe 28 unit.

Jumlah alat tangkap yang banyak akan berdampak bagi produktivitas usaha penangkapan sehingga terjadilah penurunan produksi akibat overfishing. Usaha purse seine di Negeri Latuhalat pada beberapa akhir periode belakangan ini telah merasakan dampak penurunan hasil tangkapan ikan pelagis kecil karena adanya persaingan usaha penangkapan.

Perbandingan antara hasil penjualan (output) dan biaya yang dikeluarkan (input) dengan istilah produktivitas usaha. Menurut Perkasa $d k k$, (2016) penurunan produktivitas penangkapan ikan akan meningkatkan kemiskinan nelayan. Sebagai respon atas kondisi tersebut, nelayan seringkali meningkatkan kapasitas penangkapannnya dengan menambah input produksi tanpa mempertimbangkan potensi sumber daya yang masih tersedia. Akibatnya, persaingan antar perahu menjadi lebih ketat dan industri penangkapan ikan menjadi tidak efisien. Guna menjamin keberlanjutan kegitan penangkapan ikan dan pasokan bahan baku industri pengolahan ikan, maka pada suatu usaha penangkapan ikan perlu adanya kajian untuk menganalisis produktivitasnya dengan menggunakan faktor-faktor produksi yang ada.

Usaha perikanan tangkap merupakan salah satu usaha perikanan yang memiliki karakteristik yang berbeda dengan usaha lainnya, karena penuh dengan tantangan serta dihadapkan pada risiko dan ketidakpastian. Dari sisi keuntungan atau pendapatan usaha, risiko yang dihadapi oleh nelayan adalah hasil tangkapan yang sangat bervariasi dan terkadang tidak sesuai dengan yang diharapkan (Lindawati dan Rahadian, 2016). Resiko merupakan kemungkinan kejadian yang berpotensi merugikan atau suatu keadaan ketidakpastian yang dihadapi seseorang atau usaha dan dapat memberikan dampak yang merugikan. Menurut Darmawi (2006), resiko adalah penyebaran hasil aktual dari hasil yang diharapkan. Ada tiga unsur penting dari sesuatu yang dianggap sebagai resiko yaitu merupakan suatu kejadian, yang mengandung kemungkinan, dan jika terjadi akan mengakibatkan kerugian. Pada dasarnya setiap kegiatan usaha pasti memiliki resiko. 


\section{METODE PENELITIAN \\ Metode Dasar Penelitian}

Metode yang digunakan dalam penelitian ini adalah metode survei. Metode survei adalah penyelidikan yang diadakan untuk memperoleh fakta-fakta dari gejalagejala yang ada dan mencari keteranganketerangan secara faktual, baik tentang institusi sosial, ekonomi, atau politik, dari suatu kelompok atau suatu daerah (Masyhuri dan Zainuddin, 2008).

\section{Metode Pengumpulan Data}

Teknik pengumpulan data dalam penelitian ini terdiri dari data primer dan data sekunder dimana data primer diperoleh melalui observasi, wawancara dan kuesioner, sedangkan data sekunder diperoleh dari referensi-referensi penunjang, instansi-instansi terkait dan bahan-bahan pustaka yang berhubungan dengan penelitian ini. (Sugiyono, 2013).

\section{Metode Pengambilan Sampel}

Berdasarkan jumlah populasi nelayan pemilik usaha purse seine di Negeri Latuhalat sebanyak 18 unit purse seine (DKP Kota Ambon 2015) dilakukan teknik pengambilan sampel secara purposive sampling. Berdasarkan pertimbangan tersebut diperoleh 5 unit purse seine di Negeri Latuhalat pada 2 dusun yakni Dusun Passa Rata, Dusun Waimahu yang digunakan sebagai sampel/responden dalam penelitian.

\section{Metode Analisis Data}

Data yang diperoleh dianalisis dengan metode sebagai berikut:

1. Metode analisis deskriptif kualitatif digunakan untuk menjabarkan karakteristik responden dan profil usaha purse seine di Negeri Latuhalat.

2. Metode untuk menganalis produktivitas usaha purse seine di Negeri Latuhalat adalah menggunakan persamaan menurut Tasman dan Aima (2014) bahwa produktivitas secara umum mengukur rasio output per satuan input. Maka persamaan yang digunakan dalam penelitian ini adalah:

$$
\mathrm{P}=\frac{\sum \text { Penerimaan }}{\sum \text { Biaya variabel }}
$$

di mana:

$\mathrm{P}=$ Produktivitas

Kriteria pengukuran:

$\mathrm{P}>1$ maka usaha produktif

$\mathrm{P} \leq 1$ maka usaha tidak produktif

di mana seperti di jabarkan pada persamaan diatas:

Total penerimaan (Total Revenue) dapat di rumuskan sebagai berikut:

$\mathrm{TR}=\mathrm{P} \times \mathrm{Q}$

di mana:

$\mathrm{TR}=$ Total penerimaan $(\mathrm{Rp} / \mathrm{bulan})$

$\mathrm{P}=$ Harga jual $(\mathrm{Rp} / \mathrm{Kg})$

$\mathrm{Q}=$ Jumlah produksi $(\mathrm{Kg})$

Untuk menganalisis biaya-biaya yang dikeluarkan dalam suatu usaha digunakan rumus total biaya produksi, secara matematis dapat dirumuskan sebagai berikut:

$\mathrm{TC}=\mathrm{TFC}+\mathrm{TVC}$

di mana :

$\mathrm{TC}=$ Tatal Biaya $(\mathrm{Rp} / \mathrm{bulan})$

TFC = Total biaya tetap (Rp/bulan)

TVC $=$ Total biaya variabel (Rp/bulan)

Pendapatan usaha penangkapan, secara matematis dapat dirumuskan sebagai berikut:

$\pi=\mathrm{TR}-\mathrm{TC}$

di mana:

$\pi=$ Nilai pendapatan atau keuntungan (Rp/bulan)

$\mathrm{TR}=$ Total penerimaan $(\mathrm{Rp} / \mathrm{bulan})$

$\mathrm{TC}=$ Total Biaya $(\mathrm{Rp} /$ bulan $)$

Dalam FC terdapat biaya penyusutan untuk barang modal yang di hitung dengan metode garis lurus (Habieb dan Aziz, 2014) yakni:

$$
\begin{aligned}
& \mathrm{D}=(\mathrm{P}-\mathrm{S}) / \mathrm{n} \\
& \text { di mana: } \\
& \mathrm{D}=\text { penyusutan (Rp/tahun) } \\
& \mathrm{P}=\text { nilai investasi dari masing-masing } \\
& \text { barang modal }(\mathrm{Rp}) \\
& \mathrm{S}=\text { nilai sisa }(\mathrm{Rp}) \\
& \mathrm{n}=\text { umur ekonomis (tahun) }
\end{aligned}
$$

3. Resiko usaha

Tingkat risiko usaha dapat dapat ditentukan dengan mengukur kerapatan distribusi probabilitas (Pappas dan Hirschey, 1995) dan penilaian resiko dapat dilakukan dengan mengukur nilai penyimpangan, yakni nilai harapan, varian, simpangan baku, koefisien variasi dan nilai batas bawah dari pendapatan usaha pukat cincin 
selama 3 (tiga) bulan Maret hingga Mei 2019. Persamaan nilai harapan dan varian adalah:

1) Nilai harapan

Secara matematis nilai harapan menurut Kadarsan (1995) dituliskan:

$\mathrm{Ri}=\frac{\sum_{\mathrm{j}=1}^{\mathrm{n}} \mathrm{Rij}}{\mathrm{n}}$

dimana:

$\mathrm{Ri}=$ Nilai harapan pendapatan $(\mathrm{Rp})$

Rij = Pendapatan periode ke $\mathrm{j}$, yaitu 3 bulan (Rp)

$\mathrm{n}=$ Jumlah pengamatan, yaitu selama 3 bulan

2) Varian

Secara matematis varian (ragam) menurut Sugiyono (2000) dituliskan:

$\sigma_{\mathrm{i}}^{2}=\frac{\sum_{\mathrm{j}=1}^{\mathrm{n}} \mathrm{pij}(\mathrm{Rij}-\mathrm{Ri})^{2}}{\mathrm{n}-1}$

dimana:

$\sigma_{\mathrm{i}}^{2}=$ Varian atau ragam.

Pij = Pelung dari suatu kejadian periode

ke j, yaitu 12 bulan (Rp)

$\mathrm{Ri}=$ Nilai harapan pendapatan $(\mathrm{Rp})$

$\mathrm{Rij}=$ Pendapatan periode ke $\mathrm{j}$, yaitu 3 bulan (Rp)

$\mathrm{n}=$ Jumlah pengamatan, yaitu selama 3 bulan

Secara matematis persamaan simpangan baku dan koefisien variasi (CV) dan nilai batas bawah (L) menurut Hernanto (1993) adalah:

3) impangan baku

$\sigma=\sqrt{\sigma}$

dimana:

$\sigma=$ Simpangan baku

$\sigma^{2}=$ Varian atau ragam

4) Koefisien variasi

$\mathrm{CV}=\frac{\sigma}{\mathrm{Ri}}$

dimana:

$\mathrm{CV}=$ Koefisien variasi

$\sigma=$ Simpangan baku

$\mathrm{Ri}=$ Nilai harapan pendapatan $(\mathrm{Rp})$

5) Nilai batas bawah

$\mathrm{L}=\mathrm{Ri}-2 \sigma$

dimana:

$\mathrm{L}=$ Nilai batas bawah pendapatan $(\mathrm{Rp})$

$\mathrm{Ri}=$ Nilai harapan pendapatan $(\mathrm{Rp})$

$\sigma=$ Simpangan baku

Apabila CV > 0,5 maka nilai $\mathrm{L}<0$, berarti pada setiap proses produksi ada peluang mengalami kerugian, dan apabila $\mathrm{C} \leq 0,5$ maka $\mathrm{L} \geq 0$ berarti usaha akan selalu mengalami keuntungan, serta akan impas apabila $\mathrm{CV}=0$ dan $\mathrm{L}$ $=0$ (Winarti, 2017).

\section{HASIL DAN PEMBAHASAN Karakteristik Responden}

Karakteristik responden yang akan dibahas mencakup jenis kelamin dan umur, pengalaman usaha, pendidikan, dan jumlah tanggungan dalam keluarga. Nelayan pemilik usaha purse seine di Negeri Latuhalat berumur diantara 25 hingga 65 tahun, berpendidikan terendah sekolah dasar (2 responden), sekolah menengah pertama ( 1 responden) dan tertinggi sekolah menengah atas ( 2 responden). Umur responden masih tergolong umur produktif, ditambah dengan jenjang pendidikan yang dimiliki maka produktivitas kerja sebagai nelayan pemilik usaha dapat dilakukan dengan baik. Pendidikan memberikan pengetahuan bukan saja langsung dengan pelaksaaan tugas, akan tetapi juga landasan untuk memperkembangkan diri serta kemampuan memanfaatkan semua sarana yang ada di sekitar kita untuk kelancaran pelaksanaan tugas. Semakin tinggi tingkat pendidikan semakin tinggi produktivitas kerja. Disisi lain faktor pengalaman menjalankan usaha purse seine oleh responden di antara 18 hingga 34 tahun (1 responden) dan kurang dari 18 tahun (4 responden) juga menambah pengetahun yang dimilikinya. Besarnya jumlah anggota keluarga yang akan menggunakan jumlah pendapatan yang sedikit akan berakibat pada rendahnya tingkat konsumsi. Di mana tanggungan keluarga kurang dari 3 orang ( 3 responden) dan 3 hingga 5 orang (2 responden).

\section{Profil Usaha Purse Seine}

Profil Usaha Purse Seine Secara Teknis

Modal pribadi yang dikeluarkan responden untuk memulai usaha pukat cincin di Negeri Latuhalat antara $\mathrm{Rp}$ 341.300.000,hingga $\mathrm{Rp} 368.700 .000$,- untuk pengadaan kapal/bodi, jaring, lampu, lampu petromax dan mesin penggerak kapal. Kapal penangkapan dimiliki oleh responden rata-rata berukuran panjang 17 meter, lebar 3 meter, dan tinggi 1 meter. 
Penangkapan ikan pelagis kecil segar jenis momar/layang (Decapterus spp), ikan komu/tongkol (Auxis thazard, Euthynnus affinis) dan cakalang/skipjack (Katsuwonus pelamis) umumnya dilakukan di Perairan Laut Selatan Pulau Ambon dan Perairan Laut Banda. Jumlah tenaga kerja pada usaha purse seine di Negeri Latuhalat terbanyak terdapat pada masnait dengan rata-rata jumlah tenaga kerja sebanyak 18 orang. Rata-rata jumlah tenaga kerja pada jabatan nakhoda, operator mesin dan tukang lobe sebanyak 1-2 orang. Hasil tangkapan sering didaratkan pada Pangkalan Pendaratan Ikan (PPI) Eri Kecamatan Nusaniwe dan Pasar Arumbai Mardika Kecamatan Sirimau.

\section{Profil Usaha Purse Seine Secara Ekonomi}

1. Biaya Variabel

Biaya variabel merupakan biaya yang berkaitan erat dengan operasi penangkapan. Besarnya biaya variabel berubah-ubah tergantung dari volume produksi. Biaya variabel terdiri atas biaya sarana produksi, biaya retribusi hasil tangkapan, biaya lelang, biaya transportasi, upah tenaga kerja dan biaya jasa rumpon. Jumlah biaya yang dikeluarkan pada bulan Maret oleh masingmasing responden adalah $\mathrm{Rp}$ 52.297.000,/bulan, Rp 53.013.000,-/bulan, $\quad \mathrm{Rp}$ 46.810.333,-/bulan, Rp 52.276.000,-/bulan dan Rp 48.802.000,-/bulan atau rata-rata Rp 50.639.667,-/bulan. Selanjutnya jumlah biaya yang dikeluarkan pada bulan April oleh masing-masing responden adalah $\mathrm{Rp}$ 37.275.000,-/bulan, Rp 42.821.000,-/bulan, Rp 38.388.000,-/bulan, Rp 36.389.333,/bulan dan $\mathrm{Rp} 43.144 .167,-/$ bulan atau ratarata $R p$ 47.635.267,-/bulan dan jumlah biaya yang dikeluarkan pada bulan Mei oleh masing-masing responden adalah $\mathrm{Rp}$ 25.452.333,-/bulan, Rp 26.416.000,-/bulan, Rp 28.788.667,-/bulan, Rp 22.449.000,/bulan dan Rp 25.034.000,-/bulan atau rata-rata $\mathrm{Rp} 45.596 .867,-/$ bulan.

2. Biaya Tetap

Biaya tetap (fixed cost) adalah biaya yang sifatnya tetap karena tidak tergantung atau terpengaruhi oleh perubahan volume produksi. Biaya tetap nelayan purse seine di Negeri Latuhalat hanya terdiri atas biaya penyusutan dan biaya perawatan. Jumlah biaya yang dikeluarkan pada bulan Maret oleh masing-masing responden adalah $\mathrm{Rp}$ 4.379.167,-/bulan, Rp 5.642.083,-/bulan, Rp 5.729.167,-/bulan, Rp 5.729.167,-/bulan dan $\mathrm{Rp}$ 5.632.348,-/bulan atau rata-rata $\mathrm{Rp}$ 5.438.023,-/bulan. Selanjutnya jumlah biaya yang dikeluarkan pada bulan April oleh masing-masing responden adalah $\mathrm{Rp}$ 4.429.167,-/bulan, Rp 5.492.083,-/bulan, Rp 5.542.083,-/bulan, Rp 5.807.348,-/bulan dan $\mathrm{Rp}$ 5.582.348,-/bulan atau rata-rata $\mathrm{Rp}$ $5.448 .023,-/$ bulan dan jumlah biaya yang dikeluarkan pada bulan Mei oleh masingmasing responden adalah

$\mathrm{Rp}$ 4.229.167,-/bulan, Rp 5.342.083,-/bulan, Rp 5.479.167,-/bulan, Rp 5.557.348,-/bulan dan $\mathrm{Rp}$ 5.582.348,-/bulan atau rata-rata $\mathrm{Rp}$ 5.418.023,-/bulan.

3. Total Biaya

Total biaya (total cost) adalah keseluruhan biaya yang dikeluarkan dalam proses penangkapan masing-masing unit usaha purse seine di Negeri Latuhalat selama bulan Maret, April dan Mei adalah Rp 120.844.333, Rp 135.751.250, Rp 135.751.250, Rp 125.556.379, dan $\mathrm{Rp}$ 130.930.545. Total biaya tersebut terdiri dari penjumlahan dari biaya tetap dan biaya variabel.

4. Produksi

Hasil tangkapan atau produksi usaha purse seine oleh responden adalah ikan pelagis kecil segar jenis momar/layang (Decapterus spp), ikan komu/tongkol (Auxis thazard, Euthynnus affinis) dan cakalang/skipjack (Katsuwonus pelamis). Produksi pada bulan Maret, April dan Mei relatif berbeda (Tabel 14). Produksi oleh responden tertinggi pada bulan Maret yaitu $3.955 \mathrm{~kg}, 4.095 \mathrm{~kg}, 3.605 \mathrm{~kg}, 3.990 \mathrm{~kg}$ dan $3.780 \mathrm{~kg}$. Produksi oleh responden pada bulan April yaitu $2.625 \mathrm{~kg}, 2.940$ kg, 2.695 $\mathrm{kg}, 2.590 \mathrm{~kg}$, dan $2.975 \mathrm{~kg}$ sedangkan produksi terendah adalah pada bulan Mei yaitu $1.785 \mathrm{~kg}, 1.890 \mathrm{~kg}, 2.030 \mathrm{~kg}, 1.610 \mathrm{~kg}$ dan $1.785 \mathrm{~kg}$ atau jumlah produksi oleh masing-masing respoonden adalah sebesar $6.580 \mathrm{~kg}, 7.035 \mathrm{~kg}, 6.300 \mathrm{~kg}, 6.580 \mathrm{~kg}$ dan $6.755 \mathrm{~kg}$.

5. Pemasaran

Pemasaran atau penjualan hasil tangkapan ikan segar sering dilakukan di Pelabuhan 
Pendaratan Ikan (PPI) Eri di Negeri Latuhalat Kecamatan Nusaniwe dan di Pasar Arumbai Kota Ambon. Unit purse seine dapat melakukan penjualan langsung ke konsumen atau melalui pedagang pengecer dan pengumpul, dengan rata-rata harga untuk jenis ikan momar/ layang Rp 590.000,-/loyang, ikan komu/tongkol Rp 500.000,-/loyang dan ikan cakalang/ skipjack Rp 710.000,-/loyang. Jika dikalkulasi dengan berat ikan Loyang per $35 \mathrm{~kg}$ maka harga ikan momar/layang $\mathrm{Rp}$ 16.857,-/kg, ikan komu/tongkol Rp $14.286,-/ \mathrm{kg}$ dan ikan cakalang/skipjack Rp $20.286,-/ \mathrm{kg}$ atau rata-rata harga ikan $\mathrm{Rp}$ 17.143,-/kg. Aktivitas ini memerlukan biaya transportasi, biaya lelang $(10 \%)$ dan biaya retribusi ( $\operatorname{Rp} 2000$,-/loyang).

\section{Penerimaan Usaha Purse Seine}

Hasil perhitungan penerimaan usaha diperoleh dari perkalian seluruh produksi yang telah dihasilkan dengan harga pasar. Total penerimaan usaha oleh masing-masing responden pada bulan Maret lebih besar yaitu Rp 67.800.000,-/bulan, $\quad$ Rp 70.200.000,/bulan, Rp 61.800.000,-/bulan, Rp 68.400.000,/bulan dan $\quad \operatorname{Rp} 64.800 .000,-/$ bulan dari bulan April yaitu Rp 45.000.000,-/bulan, Rp 50.400.000,-/bulan, Rp 46.200.000,-/bulan, Rp 44.400.000,-/bulan dan Rp 51.000.000,-/bulan dan dari bulan Mei yaitu Rp 30.600.000,/bulan, Rp 32.400.000,-/bulan, Rp 34.800.000,/bulan, Rp 27.600.000,-/bulan dan Rp 30.600.000,-/bulan sejalan dengan jumlah produksi yang juga lebih besar pada bulan Maret dari bulan April dan Mei.

\section{Keuntungan Usaha Purse Seine}

Keuntungan usaha purse seine yang diperoleh responden di Negeri Latuhalat merupakan selisih antara penerimaan usaha dengan total biaya yang dikeluarkan. Berdasarkan biaya total yang dikeluarkan dan penerimaan usaha, maka diperoleh jumlah keuntungan usaha oleh responden 1 sebesar $\mathrm{Rp}$ 22.555.667,- atau rata-rata $\mathrm{Rp} 7.518 .556,-$, responden 2 sebesar Rp 17.248.750,- atau ratarata $\mathrm{Rp}$ 5.749.583,-, responden 3 sebesar $\mathrm{Rp}$ 14.652.167,- atau rata-rata $\mathrm{Rp} 4.884 .056,-$, responden 4 sebesar Rp 14.843.621,- atau rata- rata $\mathrm{Rp}$ 4.947.874,-, dan responden 5 sebesar Rp 15.469.455,- atau rata-rata $\mathrm{Rp} 5.156 .485$,-

\section{Produktivitas Usaha Purse Seine}

Nilai produktivitas ke-lima responden usaha purse seine di Negeri Latuhalat pada bulan Maret hingga Mei adalah 1,28 dan 1,30. Jika didalami tiap trip sebesar 1,28 dan 1,30 menunjukkan angka yang sama. Selain itu nilai produktivitas terendah dengan nilai 1,28 untuk empat responden dan tertinggi dengan nilai 1,30 untuk satu responden. Seluruh nilai produktivitas lebih dari 1, menunjukkan bahwa usaha purse seine di Negeri Latuhalat pada bulan Maret hingga April adalah produktif. Artinya nilai produksi atau penerimaan atas penjualan ikan hasil tangkapan mampu menutupi seluruh pengeluaran dalam usaha pukat cincin di Negeri Latuhalat.

\section{Resiko Usaha Purse Seine}

Resiko usaha purse seine di Negeri Latuhalat adalah tinggi, karena dalam melakukan aktivitasnya usaha purse seine di Negeri Latuhalat berpeluang mengalami kerugian. Resiko usaha purse seine di Negeri Latuhalat dianalisis berdasarkan nilai keuntungan usaha yang diperoleh nelayan pemilik selama bulan Maret hingga Mei menunjukkan bahwa nilai koefisien variasi responden 1 sebesar 0,72 dan nilai batas bawah sebesar - 10.140.219.45, nilai koefisien variasi responden 2 sebesar 1,03 dan nilai batas bawah sebesar - 5.906.561.73, nilai koefisien variasi responden 3 sebesar 0,98 dan nilai batas bawah sebesar - 5.280.774.25, nilai koefisien variasi responden 4 sebesar 1,13 dan nilai batas bawah sebesar - 4.463.428.57 dan nilai koefisien variasi responden 5 sebesar 1,04 dan nilai batas bawah - 5.173.572.36 atau nilai $\mathrm{CV}>0,5$ dan nilai $\mathrm{L}<0$, berarti risiko usaha purse seine di Negeri Latuhalat berpeluang mengalami kerugian.

\section{KESIMPULAN}

1. Modal pribadi yang dikeluarkan responden untuk memulai usaha pukat cincin di Negeri Latuhalat antara Rp 341.300.000,- hingga Rp 368.700.000,- untuk pengadaan kapal/bodi, jaring, lampu, lampu petromax dan mesin penggerak kapal. Kapal penangkapan dimiliki oleh responden rata- 
rata berukuran panjang 17 meter, lebar 3 meter, dan tinggi 1 meter dan dan daerah penangkapan pada umumnya dilakukan di Perairan Laut Selatan Pulau Ambon dan Perairan Laut Banda

2. Usaha purse seine di Negeri Latuhalat adalah produktif dengan nilai 1,28 untuk responden 1 , responden 2 , responden 3 dan responden 5 sedangkan dengan nilai 1,30 untuk responden 4 pada bulan Maret hingga Mei.

3. Resiko usaha purse seine di Negeri Latuhalat dari bulan Maret hingga Mei (musim barat) adalah tinggi karena berpeluang mengalami kerugian sebesar Rp 10.140.219.45/bulan, Rp 5.906.561.73/bulan, Rp 5.280.774.25/bulan, Rp 4.463.428.57/bulan dan Rp 5.173.572.36/bulan.

\section{SARAN}

1. Pemilik usaha purse seine mampu untuk mengalokasikan penggunaan input secara efisien tidak mengalami kerugian akibat pengeluaran biaya yang lebih besar dibandingkan dengan penerimaan yang diperoleh agar dapat memperoleh keuntungan maksimal pada periode bukan musim ikan (musim barat).

2. Riset yang mengarah pada analisis harga dan minimalisasi penggunaan biaya pada usaha purse seine di Negeri Latuhalat perlu untuk dilakukan.

\section{DAFTAR PUSTAKA}

Balai Penelitian Laut Jakarta, 2014. Potensi dan Tingkat Pemanfaatan Sumber Daya Ikan di Wilayah Pengelolaan Perikanan Republik Indonesia (WPP RI). Penerbit Kerjasama Ref Graphik, Balai Penelitian Perikanan Laut, Pusat Penelitian Pengelolalan Perikanan dan Konservasi Sumber Daya Ikan, dan Badan Penelitian dan Pengembangan Kelautan dan Perikanan, Jakarta

Darmawi H. 2006. Manajemen Risiko. PT Bumi Aksara. Jakarta.

Dinas Kelautan dan Perikanan Provinsi Maluku. 2015. Laporan Satistik Perikanan Tangkap Dan Budidaya Provinsi Maluku.
[DKP Kota Ambon] Dinas Kelautan dan Perikanan Kota Ambon. 2015. Profil Data Perikanan DKP Kota Ambon 2015. Dinas Kelautan dan Perikanan Kota Ambon, Ambon.

Habieb, M dan Eddy Aziz, 2014. Matematika

Ekonomi dan Bisnis. Penerbit Ghalia

Indonesia. Bojongkerta.

Lindawati dan R. Rahandian. 2016. Identifikasi

Faktor dan Penilaian Risiko Pada Usaha

Perikanan Tangkap di Kabupaten

Sambas. Jurnal Sosial Ekonomi

Kelautan dan Perikanan Volume 11

Nomor 1 Juni 2016 Halaman 99-107.

Masyhuri dan Zainuddin. M, 2008. Metodologi

Penelitian: Pendekatan Praktis dan

Aplikasi. Bandung: Refika Aditama.

Pappas dan Hirschey. 1995. Ekonomi Manajerial Edisi Keenam Jilid II. Binarupa Aksara. Jakarta.

Perkasa T., D. Wijayanto, A. D. P. Fitri. 2016. Analisis Produktivitas Purse Seine garden dan Purse Seine Slerek Dengan Fishing Base di Pelabuhan Perikanan Pantai (PPP) Mucar Kabupaten Banyuwangi Jawa Timur. Journal of Fisheries Resource Utilization Management and Technology Volume 5 Nomor 1 Tahun 2016, Halaman 102110 .

Sugiyono. 2000. Statistik Untuk Penelitian. Alfabeta. Bandung.

Sugiyono. 2013. Metode Penelitian Kuantitatif Kualitatif dan RND. Penerbit Alfabet, Bandung.

Tasman A. dan H. Aima. 2014. Ekonomi Manajerial Dengan Pendekatan Matematis. Rajawali pres. Jakarta.

Winarti L. 2017. Analisis Resiko Usaha Tani Ikan Bandeng di Desa Sungai Undang Kecamatan Sruyan Hilir Kabupaten Sruyan Kalimantan Tengah. Ziraa'ah, Volume 42 Nomor 2 Juni 2017, e-ISSN 2355-3545. 


\section{PEDOMAN PENULISAN}

\section{Pedoman Umum}

a. PAPALELE, Jurnal Penelitian Ilmu Sosial Ekonomi Perikanan dan Kelautan memuat hasil penelitian yang berkaitan dengan bidang sosial ekonomi perikanan dan kelautan.

b. Naskah yang dikirim merupakan karya asli dan belum pernah diterbitkan atau dipublikasikan.

c. Naskah diketik dalam bahasa Indonesia yang baik dan benar, tidak diperkenankan menggunakan singkatan yang tidak umum.

d. Naskah diketik pada kertas A4 dengan menggunakan program microsoft word dengan 2 spasi, margin 2.5 $\mathrm{cm}$ (kiri), $2 \mathrm{~cm}$ (atas), $2 \mathrm{~cm}$ (bawah) dan 1,5 cm (kanan), font 12 times new roman, setiap halaman diberi nomor secara berurutan dengan berkolom 1 (satu), dikirim beserta soft copy maksimal 15 halaman.

e. Naskah dikirim melalui alamat ke redaksi pelaksana PAPALELE, Jurnal Penelitian Ilmu Sosial Ekonomi Perikanan dan Kelautan, Program Studi Sosial Ekonomi Perikanan Jurusan Teknologi Hasil Perikanan, Fakultas Perikanan dan Ilmu Kelautan, Universitas Pattimura, Jln. Mr. Chr. Soplanit Poka-Ambon Telp. (0911) 379859, email: inseijurnal@gmail.com.

\section{Pedoman Penulisan Naskah}

a. Judul tidak lebih dari 15 kata dalam bahasa Indonesia dan bahasa Inggris.

b. Nama lengkap penulis tanpa gelar, penulis korespondensi disertai dengan alamat email.

c. Nama lembaga/institusi disertai alamat lengkap dengan kode pos.

d. Abstrak dalam bahasa Indonesia dan bahasa Inggris tidak lebih dari 200 kata.

e. Kata kunci dalam bahasa Inggris dan Indonesia maksimal 5 kata kunci ditulis dibawah abstrak

f. Pendahuluan, memuat latar belakang, perumusan masalah, keragka teoritis dan tujuan penelitian yang dibuat secara ringkas.

g. Metodologi, memuat lokasi dan waktu penelitian, bagaimana data diperoleh dan sumbernya, bagaimana metode analisis data, jika metode yang digunakan telah diketahui sebelumnya harus dicantumkan acuannya.

h. Hasil dan Pembahasan, memuat suatu topik atau permasalahan yang terkait dengan judul, didukung dengan tabel dan gambar yang dibahas secara komperhensif, dikomplementasikan dengan referensi primer yang mendukung, update dan advance.

i. Kesimpulan dan Saran, memuat pokok-pokok bahasan serta kemampuan mengartikulasi temuan pokok untuk saran yang diberikan.

j. Ucapan terima kasih (bila diperlukan).

k. Daftar Pustaka, dicantumkan dalam naskah bila ada pengutipan dari sumber lain. Proporsi daftar pustaka yang diacu yaitu $80 \%$ merupakan rujukan primer dan $80 \%$ merupakan terbitan 10 tahun terakhir. Disusun berdasarkan abjad, dan penulisan sesuai dengan peraturan yang sudah baku, misalnya:

[KKP] Kementerian Kelautan dan Perikanan. 2012. Statistik Perikanan Tangkap 2011. Direktorat Jenderal Perikanan Tangkap Kementerian Kelautan dan Perikanan

Bataglia P, Romeo T, Consoli P, Scottie G, and Andoloro F. 2010. Characterization of The Artisanal Fishery and Its Socio-Economic aspect in The Central Menditerranean Sea (Aeolian Islands, Italy). Fisheries Research $102: 87-9$.

Pingkan W, Hamzens S, dan Sumardjo. 2007. Strategi Inovasi Sosial Pengembangan Mutu Sumberdaya Manusia Nelayan. Jurnal Penyuluhan Volume 3 Nomor 1.

Fauzi A. dan Anna S. 2005. Pemodelan Sumberdaya Perikanan dan Kelautan. Untuk Analisis Kebijakan. PT. Gramedia Pustaka Utama. Jakarta.

Wibawa T. J, Novianto D, dan Nugroho B. 2012. Sebaran Spasial Kelimpahan Ikan Cakalang (Katsuwonus Pelamis) Berdasarkan Analisis Data Satelit Oseanografi. Prosiding InSINas, 29-30 Nopember 2012.

Muksin D. 2006. Optimalisasi Usaha Perikanan Cakalang (Katsuwonus pelamis) Di Kota Tidore Kepulauan Provinsi Maluku Utara. Tesis. Program Pascasarjana IPB. Bogor.

Syandri H. 2013. Nelayan Cerdas, Nelayan Mandiri. http://www.bunghatta.ac.id/ (diunduh pada 12 September 2013).

1. Tabel, diketik dalam bahasa Indonesia, diberi judul pada bagian atas tabel, diberi nomor urut (tidak dalam bentuk JPEG).

m. Gambar dan grafik, diketik dalam bahasa Indonesia, diberi judul singkat pada bagian gawah gambar dan diberi nomor urut. 
PROGRAM STUDI AGRIBISNIS PERIKANAN

FAKULTAS PERIKANAN DAN ILMU KELAUTAN

UNIVERSITAS PATTIMURA

Jln. Mr. Chr. Soplanit, Poka - Ambon, Maluku Telepon : (0911) 379859

E-mail : inseijurnal@gmail.com

Web : http://ojs.unpatti.ac.id./index.php/insei

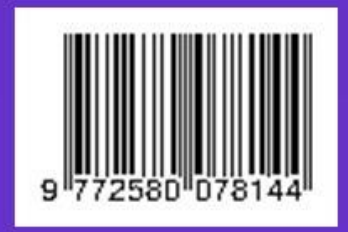

